\title{
Aceitabilidade de feijão preto (Phaseolus vulgaris L.), fortificado com micropartículas de ferro
}

\author{
Bruna Soares Ferreira ${ }^{1}$, Beatriz Trivério Cardoso' ${ }^{\text {, Heloíza Vieira Rodrigues Pereira }}{ }^{2}$, Anna Paola Pierucci \\ Cristiana Pedrosa ${ }^{3}$, Marta Citelli ${ }^{4}$
}

\begin{abstract}
RESUMO
Este trabalho teve como objetivo avaliar a aceitabilidade de feijão preto (Phaseolus vulgaris L.), fortificado com micropartículas de ferro, para que seja posteriormente utilizado na prevenção e controle da anemia ferropriva. Foram preparadas três amostras de feijão preto cozido, sendo uma sem adição de micropartículas de ferro (controle); à segunda foi adicionada quantidade equivalente a $5 \mathrm{mg}$ de ferro, para cada concha média de feijão, e, à última amostra, $10 \mathrm{mg}$ de ferro para cada concha média. Utilizou-se escala hedônica de cinco pontos para avaliação dos atributos. Com base nos resultados obtidos, as amostras controle e $5 \mathrm{mg} /$ porção foram as mais aceitas; houve, porém, pouca diferença em relação à amostra com $10 \mathrm{mg} /$ porção. A boa aceitação do alimento pelos provadores mostra ser viável a fortificação de feijão preto com ferro microencapsulado, podendo ser usado na prevenção e controle da anemia ferropriva.
\end{abstract}

Palavras-chave: Fortificação de alimentos, ferro microencapsulado, análise sensorial, anemia ferropriva.

\begin{abstract}
Acceptability of black beans (Phaseolus vulgaris L.) fortified with iron microparticles

This study aimed to evaluate the acceptability of black beans (Phaseolus vulgaris L.) fortified with iron micro particles, to be further used in the prevention and control of iron-deficiency anemia. Three samples of stewed black bean were prepared: 1) no addition of microencapsulated ferrous sulfate (control); 2) $5 \mathrm{mg}$ of iron were added to each serving spoon of beans; and 3)10 mg of iron added to each serving spoon of beans. A 5-point hedonic scale was used to evaluate the attributes. The samples from the control and the treatment with $5 \mathrm{mg}$ iron/serving spoon had better acceptance, but there was a little difference when the $5 \mathrm{mg} / \mathrm{serving}$ was compared with the $10 \mathrm{mg} / \mathrm{serving}$. The high acceptability by the sensory panelists indicates that the fortification of black beans with microencapsulated iron is viable and that it can be used to prevent and control iron- deficiency anemia.
\end{abstract}

Key words: Anemia, fortified foods, iron deficiency, microencapsulated iron, sensory analysis.

\footnotetext{
Recebido para publicação em 30/07/2010 e aprovado 12/09/2011

${ }^{1}$ Nutricionista. Instituto de Nutrição Josué de Castro, Centro de Ciências da Saúde, Universidade Federal do Rio de Janeiro,- Avenida Carlos Chagas Filho, 373, bloco J, sub-solo, sala 08, Ilha do Fundão, 21941-590, Rio de Janeiro, Rio de Janeiro, Brasil. bruna_soaresrj@hotmail.com, biatriverio@yahoo.com.br

${ }^{2}$ Nutricionista, Mestre. Instituto de Nutrição Josué de Castro, Centro de Ciências da Saúde, Universidade Federal do Rio de Janeiro, Avenida Carlos Chagas Filho, 373 , bloco J, subsolo, sala 08, Ilha do Fundão, 21941-590, Rio de Janeiro, Rio de Janeiro, Brasil. Brasil. helovrp@ gmail.com

${ }^{3}$ Nutricionista, PhD. Instituto de Nutrição Josué de Castro, Centro de Ciências da Saúde, Universidade Federal do Rio de Janeiro, Avenida Carlos Chagas Filho, 373, bloco J, subsolo, sala 08, Ilha do Fundão, 21941-590, Rio de Janeiro, Rio de Janeiro, Brasil. cristiana@ nutricao.ufrj.br, appierucci@gmail.com

${ }^{4}$ Nutricionista, PhD. Departamento de Nutrição Básica Experimental, Centro Biomédico, Universidade do Estado do Rio de Janeiro, Rua São Francisco Xavier, 524, 12 andar, Maracanã, 20550-900, Rio de Janeiro, Rio de Janeiro, Brasil. martacitelli@yahoo.com.br
} 


\section{INTRODUÇÃO}

A carência de ferro, incluindo a sua forma mais severa, a anemia, é a deficiência nutricional mais comum em todo o mundo. Ela não só afeta um grande número de crianças e mulheres em países não industrializados, mas, também, é a única deficiência nutricional que é, de igual forma, significativamente predominante em praticamente todas as nações industrializadas. Não há números globais atuais para indicar a deficiência de ferro, mas, usando-se as ocorrências de anemia como um indicador indireto, podese estimar que a maioria das crianças pré-escolares e as mulheres grávidas, nos países não industrializados, e, pelo menos de 30 a 40\%, nos países industrializados, são deficientes em ferro (WHO, 2001).

Embora a dieta seja o principal fator, nem sempre é a causa exclusiva da anemia. Outras deficiências nutricionais, infestações parasitárias e infecções exercem um papel importante, em ocorrências de anemia, em países tropicais (Kasili, 1990).

Apesar da ausência de um levantamento nacional, existe consenso na comunidade científica de que a Anemia por Deficiência de Ferro é o problema nutricional de maior amplitude no Brasil, atingindo todas as classes de renda. Estudos locais recentes indicam prevalências de Anemia por Deficiência de Ferro em, aproximadamente, $50 \%$ dos pré-escolares (cerca de 4,8 milhões de crianças), e estimase uma média nacional em torno de $30 \%$, em gestantes brasileiras (Ministério da Saúde, 2005). No Estado de São Paulo, estudos epidemiológicos sobre anemia mostraram aumento de mais de $100 \%$, nas últimas duas décadas, em crianças menores de cinco anos, inclusive entre a população de melhor poder aquisitivo(Monteiro et al., 2000).

As repercussões da anemia sobre o organismo humano interferem no crescimento, no desenvolvimento físico e mental de crianças, acarretando sonolência, incapacidade de fixar a atenção e diminuição na acuidade mental, levando ao comprometimento do rendimento escolar. Nessa faixa etária, pode, também, provocar redução da capacidade imunológica, acarretando maior sensibilidade à toxicidade por metais pesados, maior susceptibilidade às infecções, alta morbidade e mortalidade e, ainda, danos à regulação térmica, no caso da anemia severa (WHO, 1998). A deficiência de ferro durante a gravidez tem sido relacionada com o aumento da morbidade e da mortalidade de gestantes, assim como do feto. $\mathrm{Na}$ anemia ferropriva a relação entre a anemia da gestante e o risco de nascimento de crianças prematuras parece específica (Scholl et al., 1992).

Diante desse quadro, uma forma excelente de prevenção e combate a essa carência é a fortificação alimentar. A biofortificação tem emergido como alternativa recente para complementar os programas de intervenção nutricional e reduzir os problemas de deficiências de vários micronutrientes, dentre eles o ferro, e caracteriza-se pelo aumento do conteúdo de nutrientes nos alimentos, por meio de melhoramento genético convencional ou da engenharia genética (Pfeiffer \& McClafferty, 2007; Rios et al., 2009).

Além dessa forma de fortificação, a OMS reconhece quatro outros tipos. A "fortificação em massa ou universal", que consiste na adição de micronutrientes aos alimentos consumidos pela grande maioria da população, sendo regulada pelos governos. É indicada em países onde diferentes grupos populacionais apresentam risco elevado de desenvolvimento de anemia. A "fortificação em mercado aberto", por iniciativa da indústria de alimentos em fortificar seus produtos, com o objetivo de aumentar seus lucros. A “fortificação direcionada", que consiste na fortificação de alimentos consumidos por grupos de alto risco de anemia. E, por último, a "fortificação comunitária ou domiciliar", uma nova abordagem que está sendo explorada em países em desenvolvimento (Lynch, 2005) e que consiste no fornecimento do nutriente, geralmente microencapsulado e apresentado sob a forma de pó (sprinkles), o qual é distribuído sobre a preparação.

Em todo o mundo, a fortificação de alimentos é considerada a solução mais prática e de melhor custo-benefício, sobretudo para regiões nas quais há grande prevalência dessa carência nutricional (Beinner \& Lamounier, 2003; Lynch, 2005; WHO, 2001).

Existem alguns critérios para a seleção dos alimentos a serem fortificados, tais como: consumo por toda a população-alvo, pequena variação per capita no consumo semanal, não ocorrência de alterações nas características organolépticas do produto, boa aceitabilidade, biodisponibilidade do nutriente no alimento, viabilidade econômica, razoável segurança frente ao risco de ingestão excessiva e estabilidade sob condições padrão de armazenamento (Berg, 1984; Raunhardt \& Bowley, 1996).

Há muitos compostos à base de ferro que podem ser utilizados na fortificação; há, no entanto, problemas técnicos na escolha de tais componentes. Os compostos de biodisponibilidade relativamente alta, como o sulfato ferroso, costumam provocar alterações sensoriais não toleradas, enquanto outros compostos mais aceitáveis são minimamente absorvidos (Hurrell et al., 2002). Para tanto, foi desenvolvida a técnica de microencapsulamento, que, ao isolar o ferro, mascara seu sabor, reduz a reatividade com outros componentes dos alimentos e pode, ainda, controlar a sua liberação em áreas do trato gastrintestinal, levando a uma melhor absorção(Ré, 2000). O sulfato ferroso contido nas micropartículas empregadas nesta investigação mostrou-se tanto ou mais biodisponível que o sulfato ferroso livre, tal como demonstrado por experimentos feitos com a utilização de um modelo de liberação e de absorção in vitro, com células Caco-2 (Bittencourt, 2011). 
O interesse por materiais com capacidade encapsulante vem crescendo sobremaneira, com o objetivo de encontrar novas alternativas de materiais naturais, de baixo custo e biocompatíveis, no desenvolvimento de alimentos para diversos fins. Proteínas de sementes de leguminosas, como de ervilha (PPC - "pea protein concentrate"), usadas neste trabalho, parecem atender a essa demanda, ganhando crescente atenção em relação ao seu uso como agente funcional no desenvolvimento de alimentos (Pedrosa et al., 2000; Pereira et al., 2009).

Esta pesquisa utilizou análise sensorial para avaliar a aceitação de feijão preto, fortificado com uma formulação de sulfato ferroso microencapsulado.

Por ser um alimento de fácil acesso à população, de baixo custo e estar inserido na cultura alimentar brasileira, o feijão comum foi escolhido para a realização deste trabalho. A escolha do feijão do grupo comercial de cor preta deve-se ao fato de este ser menos propenso à variação de cor decorrente das reações químicas do alimento com o ferro microencapsulado, evitando-se, assim, sua possível rejeição por parte da população alvo.

\section{MATERIAL E MÉTODOS}

Este trabalho foi realizado no laboratório de Técnica Dietética e no Laboratório de Desenvolvimento de Alimentos para Fins Especiais e Educacionais, da Universidade Federal do Rio de Janeiro.

A matéria prima utilizada foi o feijão preto (Phaseolus vulgaris $\mathrm{L}$.) tipo 1, obtido em mercado varejista local. $\mathrm{O}$ PPC foi gentilmente cedido pelo Labonathus Laboratório (Brasil). O material encapsulado foi $\mathrm{FeSO}_{4}$, da empresa Vetec Química Fina (Brasil).

\section{Produção das micropartículas}

A produção e a caracterização das micropartículas de ferro estão sendo submetidas a um processo de patente. A quantidade de ferro contida nas micropartículas foi determinada por espectrometria de absorção atômica (Bittencourt, 2011).

\section{Preparo das amostras}

O preparo do feijão preto foi feito segundo o procedimento caseiro, utilizando-se $1 \mathrm{~kg}$ de feijão preto, previamente lavado em água corrente, 5 folhas de louro, $18 \mathrm{~g}$ de sal, $60 \mathrm{ml}$ de óleo, $100 \mathrm{~g}$ de cebola, $10 \mathrm{~g}$ de alho e 2,5 L de água filtrada. A preparação foi cozida em panela de pressão, em fogão do tipo caseiro e, ao final do preparo, foram separadas três frações iguais de feijão, mantendo-se o caldo na amostragem de cada fração. A primeira não recebeu a adição de sulfato ferroso microencapsulado (controle), à segunda fração foi adicionada uma quantidade equivalente a $5 \mathrm{mg}$ de ferro para cada concha média de feijão, e uma terceira recebeu $10 \mathrm{mg}$ de ferro para cada concha.

\section{Análise sensorial}

A aceitação de feijão preto, fortificado com diferentes concentrações de micropartículas de ferro, foi avaliada por meio de um teste afetivo, utilizando-se provadores não treinados, selecionados aleatoriamente. O teste foi realizado, dentro da própria universidade, com 54 indivíduos, dentre eles, alunos, funcionários e professores, com idade entre 19 e 67 anos, sendo $85 \%$ do sexo feminino. Os provadores responderam a um questionário e assinaram um termo de consentimento para a participação no estudo.

Cada participante recebeu cerca de $20 \mathrm{~g}$ de cada amostra, que recebeu números aleatórios de identificação de três dígitos. A ordem das amostras era trocada a cada novo provador.

Utilizou-se escala hedônica de cinco pontos, para os seguintes atributos: sabores amargo, salgado e metálico, variando de "muito forte" (1 ponto) a "muito fraco"(5 pontos) e ponto central como "nem forte, nem fraco (não percebi)" (3 pontos). Para a qualidade global, os valores utilizados foram de "muito bom" (1 ponto), a "muito ruim" (5 pontos), tendo como ponto central o valor "regular" (3 pontos).

\section{Análise estatística}

Os resultados da avaliação sensorial das amostras foram tratados estatisticamente pela análise de variância ANOVA “one-way", a 5\% de significância, empregandose o software SPSS, versão 12.

\section{RESULTADOS E DISCUSSÃO}

As amostras não diferiram, em relação às médias atribuídas para percepção dos sabores amargo, salgado e metálico (Tabela 1), sendo todas correspondentes a valores próximos ao escore 3 , equivalente a "Nem forte, nem fraco - não percebi" da escala hedônica, sinalizando que, de forma geral, os provadores não sentiram tais sabores de forma muito acentuada nas três amostras testadas.

Escalas hedônicas maiores (mais intervaladas), apesar de mais abrangentes e amplamente utilizadas, não fa-

Tabela 1. Valores médios atribuídos pela análise sensorial de feijão preto cozido quanto aos sabores amargo, salgado e metálico, em uma escala hedônica de 1 (muito forte) a 5 (muito fraco)

\begin{tabular}{lccc}
\hline Amostras & $\begin{array}{c}\text { Sabor } \\
\text { Amargo }\end{array}$ & $\begin{array}{c}\text { Sabor } \\
\text { Salgado }\end{array}$ & $\begin{array}{c}\text { Sabor } \\
\text { Metálico }\end{array}$ \\
\hline Controle & $3,67 \pm 0,97$ & $3,57 \pm 0,71$ & $3,54 \pm 1,04$ \\
5mg/porção* & $3,33 \pm 1,06$ & $3,56 \pm 0,92$ & $3,30 \pm 0,92$ \\
10mg/porção* & $3,17 \pm 1,02^{\text {a }}$ & $3,48 \pm 0,96$ & $3,00 \pm 1,21^{\text {a }}$ \\
\hline * Porção equivalente a uma concha média. & \\
a - Indica diferença significativa $(\mathrm{p}<0,05)$ em relação ao Controle.
\end{tabular}


cilitam a escolha afetiva de provadores não treinados e acarretariam um amplo espectro de respostas afetivas, para uma amostra que não apresenta grande variabilidade entre os atributos analisados. Com isso, a decisão por escala de 5 pontos baseou-se, principalmente, na busca por respostas mais semelhantes, para garantir melhor sensibilidade do teste. Futuramente, dados serão novamente colhidos, com diferentes concentrações de ferro microencapsulado, com aplicação de escalas com maiores graus hedônicos.

A escolha de veículo adequado é consideração de suma importância em qualquer tentativa de fortificar alimentos. Produtos de cereais têm sido tradicionalmente usados como veículos para a fortificação de ferro, em muitos países. Outros veículos usados incluem açúcar, molho de peixe, sal comum, e bolinhos (Sari et al., 2001). O fato de ser alimento típico da alimentação do brasileiro faz do feijão fortificado instrumento de grande valor no combate e prevenção da anemia carencial.

Foi constatado, por um grupo de consultores da UNICEF, em 1996, que as alternativas disponíveis (xarope e gotas para lactentes e crianças, cápsulas para as mulheres) não são eficazes. A adesão ao tratamento é baixa, apesar dos esforços múltiplos para influenciar e melhorar. Sabe-se que um dos fatores preponderantes, com relação à não aceitação de alimentos fortificados com ferro, diz respeito ao sabor metálico característico (Zlotkin et al., 2001).

O uso da técnica de microencapsulamento de sulfato ferroso tem se mostrado boa alternativa para proteger os alimentos de alterações sensoriais indesejáveis e evitar a oxidação do sulfato ferroso (Cocato et al., 2007). Tendo em vista que um dos objetivos principais do microencapsulamento do ferro é o mascaramento de suas características indesejáveis, sobretudo com relação ao sabor metálico, obteve-se excelente resultado, no presente estudo, que pode ser evidenciado pela Figura 1.

O sabor metálico não foi percebido por grande parte dos provadores, principalmente nas amostras controle e $5 \mathrm{mg}$ de ferro, que mostram resultados bastante semelhantes para a frequência do escore 3 (Nem forte, nem fraco - não percebi), indicando ser este um possível meio bastante simples e viável de fortificação, no país. A amostra com 10 mg de ferro por porção não obteve resultados muito favoráveis, em relação ao sabor metálico. Isso já era esperado, tendo em vista que tal amostra contém em si excessiva quantidade de ferro. Essa quantidade não se faz necessária, já que alimentos fontes de ferro, que fazem parte da alimentação cotidiana, serão possivelmente incluídos ao longo do dia.

O fornecimento do nutriente para ser distribuído diretamente sobre a preparação, que caracteriza a fortificação caseira, tem-se mostrado boa opção, pois representa grande economia em termos de custo de transporte e armazenamento, além da questão da melhor aceitação. De acordo com Zlotkin et al. (2005), a fortificação feita dessa forma é mais eficiente por tornar possível a ingestão de grande quantidade de ferro em uma única refeição, principalmente para os grupos mais afetados, representados por pré-escolares e gestantes. De fato, neste estudo, houve boa aceitação do feijão, quando foram adicionados cerca de $5 \mathrm{mg}$ de ferro em uma porção (1 concha média), quantidade superior a $50 \%$ das recomendações diárias de referência da maior parte dos grupos em diferentes estágios de vida, sendo igual a $0,27 \mathrm{mg} /$ dia para lactentes de 0 a 6 meses, $9 \mathrm{mg} /$ dia para lactentes de 7 a 11 meses, $6 \mathrm{mg} / \mathrm{dia}$ para crianças de 1 a 3 e 4 a 6 anos e $9 \mathrm{mg} /$ dia para aquelas de 7 a 10 anos. A recomendação para adultos é de $14 \mathrm{mg} /$ dia. Há ainda recomendações para gestantes e lactantes, cujos valores são, respectivamente, 27 e $15 \mathrm{mg} / \mathrm{dia}$ (ANVISA, 2005).

De acordo com Pierucci et al. (2007), a matéria-prima empregada como material encapsulante (PPC) apresenta relativo baixo custo, sendo considerado material potencial para aplicação na produção de alimentos de baixo custo. Contudo, não foi objetivo deste trabalho avaliar o custo de produção em larga escala desse material. Este estudo preliminar fornece bases para futuros investimentos na produção de micropartículas de ferro para aplicação em alimentos.

A qualidade global analisa a avaliação de todo o aspecto da amostra, incluindo aparência, cor e consistência. Na Tabela 2, mostra-se que grande parte dos provadores atribuíram à amostra controle o valor 2 (bom). A amostra controle apresentou a melhor aceitação; porém, a amostra com $5 \mathrm{mg}$ de ferro apresenta média muito próxima à apresentada pela primeira.

De modo geral, as amostras tiveram boa aceitação, obtendo média de aceitação próxima ao escore 2 (bom). Porém, como pode ser observado na Figura 2, somente as amostras controle e com $5 \mathrm{mg}$ de ferro alcançaram médias de aceitação satisfatórias (bom e muito bom) por mais de $50 \%$ dos provadores. Apenas a amostra com $10 \mathrm{mg}$ de ferro foi avaliada como "muito ruim" ( 5 pontos) por parte de alguns provadores.

Tabela 2. Valores médios atribuídos pela análise sensorial de feijão preto cozido quanto à qualidade global das amostras de feijão, variando de 1 (muito bom) a 5 (muito ruim)

\begin{tabular}{|c|c|}
\hline Amostras & Qualidade global \\
\hline Controle & $2,15 \pm 0,71$ \\
\hline $5 \mathrm{mg} /$ porção & $2,46 \pm 0,84$ \\
\hline $10 \mathrm{mg} /$ porção & $2,85 \pm 0,98^{\mathrm{ab}}$ \\
\hline
\end{tabular}

Rev. Ceres, Viçosa, v. 58, n.5, p. 548-553, set/out, 2011 


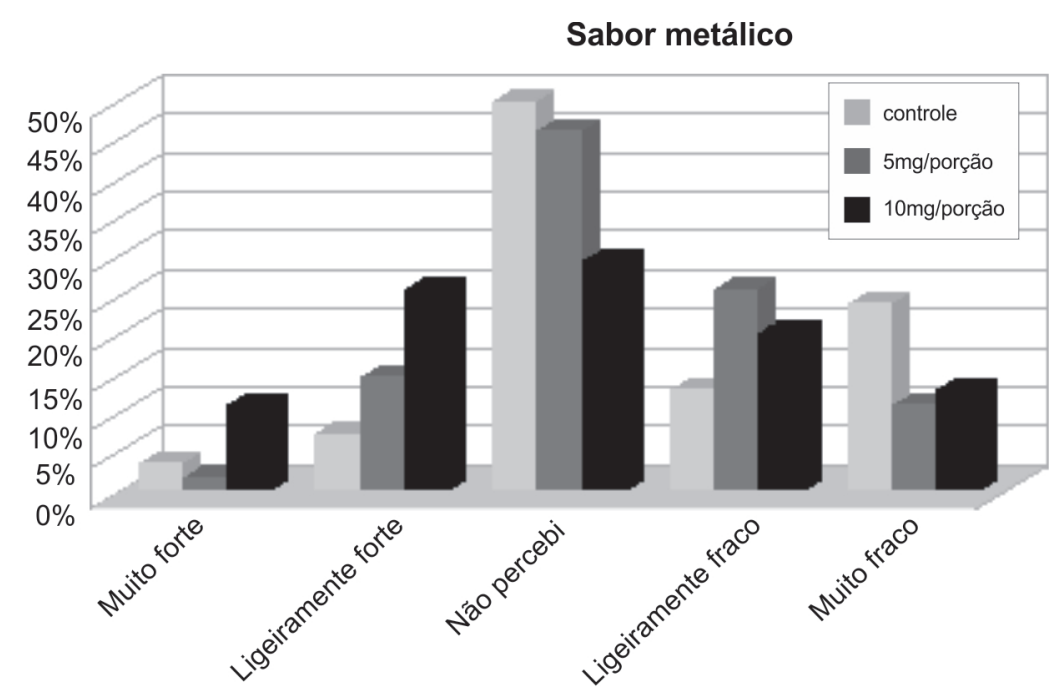

Figura 1. Distribuição percentual da frequência de atribuição do sabor metálico das amostras cozidas de feijão preto controle, $5 \mathrm{mg}$ de ferro/porção e $10 \mathrm{mg}$ de ferro/porção.

Os resultados evidenciam que a amostra fortificada com $5 \mathrm{mg}$ de ferro seria bem aceita pela população. Isso pode ser destacado pela boa aceitação por parte dos provadores, obtendo cerca de $60 \%$ no somatório das notas "bom" e "muito bom", e também pela não atribuição da nota "muito ruim" por nenhum dos provadores.

Souto et al. (2008), analisando a aceitabilidade de pão fortificado com ferro microencapsulado, por crianças de creches de São Paulo, concluíram que este, apesar de apresentar diferença de sabor observada pelas crianças, teve boa aceitabilidade em relação ao pão não fortificado.

Pesquisas utilizando leite, pão, biscoitos e sucos fortificados para crianças - as quais constituem um dos principais grupos de interesse - obtiveram aceitação referida como boa; os alimentos, porém, não foram comparados com similares não fortificados, o que, certamente, daria maior credibilidade aos resultados (Torres et al., 1994; Fisberg et al., 1998; Almeida et al., 2003).

Pode-se atribuir a baixa aceitação do feijão fortificado com $10 \mathrm{mg}$ de ferro à forma como as amostras foram servidas, fazendo que as diferenças de cores entre as diferentes amostras fossem percebidas, tendo em vista que as amostras foram entregues simultaneamente, permitindo que houvesse comparação do aspecto visual. Conjecturase que, se as amostras fossem servidas separadamente, talvez essa diferença não fosse percebida e a amostra com $10 \mathrm{mg}$ de ferro seria mais bem aceita, já que para a percepção de sabor, os resultados não diferiram significativamente entre as amostras.

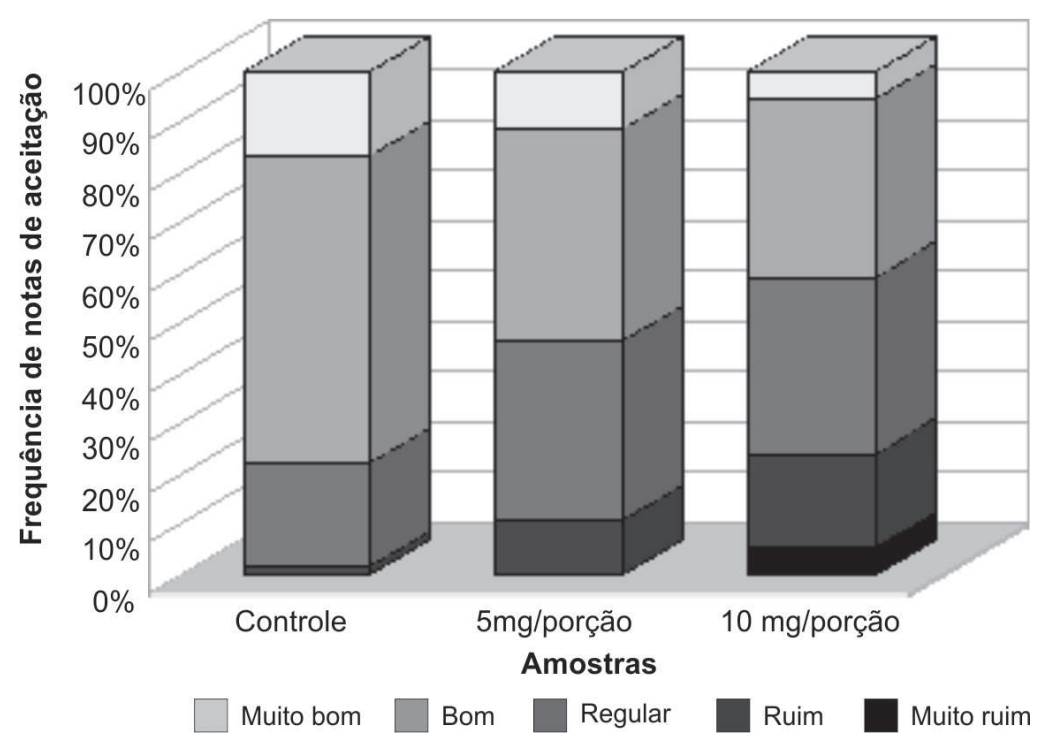

Figura 2. Distribuição percentual da frequência de notas de aceitação para o escore "qualidade global" de feijão preto cozido. 


\section{CONCLUSÃO}

Não houve diferença significativa $(\mathrm{p}>0,05)$ entre as amostras adicionadas com zero (controle), $5 \mathrm{mg}$ e $10 \mathrm{mg}$ de sulfato ferroso microencapsulado, por porção de feijão preto, em relação aos sabores metálico, salgado e amargo. Quanto à qualidade global, não houve diferença significativa da amostra controle e adicionada de $5 \mathrm{mg}$ de ferro, mas a porção de feijão, fortificada com $10 \mathrm{mg}$ de ferro, apresentou aceitação significativamente menor que as amostras controle e adicionada de $5 \mathrm{mg}$ de ferro $(\mathrm{p}<0,05)$. A fortificação de feijão preto com $5 \mathrm{mg}$ de ferro por porção foi bem aceita sensorialmente, o que pode ser decorrente da capacidade de mascarar o sabor metálico do ferro, exercida pelo microencapsulamento.

\section{AGRADECIMENTOS}

Ao Laboratório de Análise e Processamento de Alimentos - LAPAL / INJC e ao Laboratório de Desenvolvimento de Alimentos para Fins Especiais e Educacionais (DAFEE), da Universidade Federal do Rio de Janeiro. Este trabalho foi desenvolvido com verbas da Fundação de Amparo à Pesquisa do Estado do Rio de Janeiro (FAPERJ).

\section{REFERÊNCIAS}

Almeida CA, Crott GC, Ricco RG, del Ciampo LA, Dutra de Oliveira JE \& Cantolini A (2003) Control of irondeficiency anaemia in Brazilian preschool children using iron-fortified orange juice. Nutrition Research, 23:27-33.

Agência Nacional de Vigilância Sanitária - ANVISA (2005) Resolução RDC no 269, de 22 de setembro de 2005. Regulamento técnico sobre a ingestão diária recomendada (IDR) de proteína, vitaminas e minerais. Disponível em: <http://e-legis.bvs.br/leisref/public/ showAct.php?id=18828\&word >. Acessado em: 1 de julho de 2011 .

Beinner MA \& Lamounier JA (2003) Recent experience with fortification of foods and beverages with iron for the control of iron-deficiency anemia in Brazilian children. Food and Nutrition Bulletin, 24:268-274.

Berg A (1984) The nutrition factor: its role in national development. Washington (DC), Institute for Policy Studies.

Bittencourt, LLA (2011) Micropartículas de ferro para fortificação de alimentos. Rio de Janeiro, 2011. Dissertação de Mestrado. Instituto de Nutrição Josué de Castro, Universidade Federal do Rio de Janeiro, Rio de Janeiro. 96p.

Cocato ML, Ré MI, Trindade Neto MA, Chiebao HP \& Colli C (2007) Avaliação por métodos in vitro e in vivo da biodisponibilidade de sulfato ferroso microencapsulado. Revista de Nutrição, 20:239-247.

Fisberg M, Velloso EP, Ribeiro RMS, Zuelo M, Braga JAP \& Neto CS (1998) Anemia ferropriva e estratégias de fortificação com ferro aminoquelato. Pediatria Atual, 11:19-26.

Hurrell R, Bothwell T, Cook JD, Dary O, Davidsson L \& Fairweather-Tait S (2002) The usefulness of elemental iron for cereal flour fortification: a sharing united states technology to aid in the improvement of nutrition-SUSTAIN Task Force report. Nutrition Reviews, 60:391-406.

Kasili EG (1990) Malnutrition and infections as causes of childhood anemia in tropical Africa. American Journal of Pediatrics Hematology Oncology, 12:375-377.
Lynch SR (2005) The impact of iron fortification on nutritional anaemia. Best Practice \& Research Clinical Haematology, 18:333-346.

Ministério da Saúde, Secretaria de Atenção à Saúde, Departamento de Atenção Básica (2005) Manual Operacional do Programa Nacional de Suplementação de Ferro - Brasília, Ministério da Saúde. 28p. - (Série A. Normas e Manuais Técnicos).

Monteiro CA, Szarfarc SC \& Mondini L (2000) Tendência secular da anemia na infância na cidade de São Paulo (1984-1996). Revista de Saúde Pública, 34:62-72.

Pedrosa C, De Felice FG, Trisciuzzi C \& Ferreira ST (2000) Selective neoglycosylation increases the structural stability of vicilin, the 7S storage globulin from pea seeds. Archives of Biochemistry and Biophysics, 382:203-210.

Pereira HVR, Saraiva KP, Carvalho LMJ, Andrade LR, Pedrosa C \& Pierucci APTR (2009) Legumes seeds protein isolates in the production of ascorbic acid microparticles. Food Research International, 42:115-121.

Pfeiffer WH \& McClafferty B (2007) HarvestPlus: breeding croops for better nutrition. Crop Science, 47:88-105.

Pierucci APTR, Andrade LR, Farina M, Pedrosa C \& Rocha-Leão MHM (2007) Comparison of á-tocopherol microparticles produced with different wall materials: pea protein a new interesting alternative. Journal of Microencapsulation, 24:201-213.

Raunhardt O \& Bowley A (1996) Mandatory food enrichment. Nutriview, 1:1-44. (Supl).

Ré MI (2000) Microencapsulação: em busca de produtos 'inteligentes'. Ciência Hoje, 27:24-29.

Rios SA, Alves KR, Costa NMB \& Martino HSD (2009) Biofortificação: culturas enriquecidas com micronutrientes pelo melhoramento genético. Revista Ceres, 56:713-718.

Sari M, Bloem MW, de Pee S, Schultink WJ \& Sastroamidjojo S (2001) Effect of iron-fortified candies on the iron status of children aged 4-6 y in East Jakarta, Indonesia. American Journal of Clinical Nutrition, 73:1034-1039.

Scholl TO, Hediger ML, Fischer RL \& Shearer JW (1992) Anemia vs iron deficiency: increased risk of preterm delivery in a prospective study. American Journal of Clinical Nutrition, 59:985-988.

Souto TS, Brasil ALD \& Taddei JAAC (2008) Aceitabilidade de pão fortificado com ferro microencapsulado por crianças de creches das regiões sul e leste da cidade de São Paulo. Revista de Nutrição, 21:647-657.

Torres MA, Sato K, Novo NF \& Queiroz SS (1994) O leite fortificado no controle da anemia carencial ferropriva, em crianças matriculadas nas creches municipais da Grande São Paulo. Boletim da Sociedade Brasileira de Hematologia e Hemoterapia, 16:221-227.

World Health Organization (1998) Preventing Iron Deficiency in Women and Children. Technical Workshop. Boston: International Nutrition Foundation: Disponível em: < http://inffoundation.org/ pdf/prevent_iron_def.pdf >. Acessado em: 16 de novembro de 2009.

World Health Organization (2001) Iron deficiency anaemia: assessment, prevention, and control. Geneva: World Health Organization, (WHO/NHD/01.3). Disponível em: <http:// www.who.int/nutrition/publications/micronutrients/ anaemia_iron_deficiency/WHO_NHD_01.3/en/index.html>. Acessado em: 12 de novembro de 2009.

Zlotkin SH, Arthur P, Antwi KY \& Yeung G (2001) Treatment of anemia with microencapsulated ferrous fumarate plus ascorbic acid supplied as sprinkles to complementary (weaning) foods. American Journal of Clinical Nutrition, 74:791-795.

Zlotkin SH, Schauer C, Christofides A, SharieffW, Tondeur MC \& Hyder SM (2005) Micronutrient sprinkles to control childhood anaemia. PloS Medicine, 2:0024-0028. 